\title{
Sociodemographic and clinical characteristics of patients with diabetic foot ulcer
}

\author{
Susana Pedras ${ }^{1 *}$, Ru Carvalho ${ }^{2}$, Maria da Graça Pereira ${ }^{3}$ \\ ${ }^{1}$ MSc in Health Psychology - PhD Student, School of Psychology, Universidade do Minho, Braga, Portugal \\ ${ }^{2}$ Endocrinologist - Director of the Diabetic Foot Clinic at Centro Hospitalar do Porto, Porto, Portugal \\ ${ }^{3} \mathrm{PhD}$ - Associate Professor at School of Psychology, Universidade do Minho, Braga, Portugal
}

Study conducted at Escola de Psicologia, Universidade do Minho, Braga, Portugal

Article received: $7 / 16 / 2014$ Accepted for publication: 10/21/2014

*Correspondence: Address: Escola de Psicologia Universidade do Minho Braga, Portugal Postal code: $4710-057$ susanapedras@gmail.com

Financial support: This study was conducted at the Psychology Research Centre (PSI/01662), University of Minho, and supported by the Portuguese Foundation for Science and Technology and the Portuguese Ministry of Science, Technology and Higher Education through national grants and co-funded by the FEDER through COMPETE2020 under the PT2020 Partnership Agreement (POCl-01-0145-FEDER-007653)

http://dx.doi.org/10.1590/1806-9282.62.02.171

\section{SUMmARY}

Introduction: Diabetic foot is one of the most serious complications of diabetes affecting about $15 \%$ of all diabetes patients, and it is the leading cause of nontraumatic lower limb amputations. This study presents a sociodemographic and clinical characterization of patients with diabetic foot ulcer indicated for amputation surgery.

Methods: A cross-sectional study with 206 patients with type 2 diabetes and a diabetic foot ulcer indicated for amputation surgery. Patients were assessed on sociodemographic and clinical characteristics, pain intensity and pain interference, after answering the Brief Pain Inventory, and on pain descriptors according to the Douleur Neuropathique 4.

Results: Most patients were male, with little formal education and a mean age of 66 years. They had been diagnosed with type 2 diabetes for 18 years in average, and diagnosed with diabetic foot ulcer in average 3 years prior to the assessment. About $59 \%$ of patients experienced pain in the lower limb that significantly interfered with all areas of their functioning.

Conclusion: The social demographic variables play an important role in diabetic foot ulceration. Given that the neuropathic ulcers are more easily preventable, systematic monitoring of patients with neuropathy is important. In patients with neuroischemic foot, strategies to cope or manage more efficiently the pain are paramount. Intervention should be multidisciplinary and take into account sociodemographic and clinical factors, as well as the presence, intensity and interference of pain in the patient's daily life activities and whether the patient has family or caregiver support.

Keywords: type 2 diabetes mellitus, diabetes complications, diabetic foot.

\section{INTRODUCTION}

Around $13 \%$ of the Portuguese population has diabetes, which corresponds to an estimated 1 million individuals, aged between 20 and 79 years. ${ }^{1}$

Diabetes is a complex chronic disease that requires regular medical follow-up. ${ }^{2}$ Diabetes care involves a change in lifestyle (healthy eating, physical activity, stopping smoking, weight control and effective problem-solving strategies), self-management of the disease (adherence to the medication, self-monitoring of blood glucose) and the prevention of complications (adherence to foot care and screening for vision and kidney problems). ${ }^{2}$

The persistence of a high level of glucose in the blood results in tissue damage. These lesions may be found in various organs but their manifestation at the level of the kidneys, eyes, nerves and peripheral vascular system are the most important. ${ }^{1}$ The main complications of diabetes are diabetic retinopathy, diabetic neuropathy, nephropathy and atherosclerotic vascular diseases such as peripheral vascular disease (PVD), coronary heart disease and cerebrovascular disease. ${ }^{3}$

Diabetic foot ulcer (DFU) is a term used to designate lesions that can occur in a diabetes patient's foot. It has a neuropathic etiopathogenic basis, caused by chronic hyperglycemia which, in the absence or presence of $\mathrm{PVD}$, and due to prior trauma in the foot, causes ulceration. This problem represents one of the most serious complications of diabetes, affecting approximately $15 \%$ of all diabetic in- 
dividuals, and constitutes the leading cause of non-traumatic amputation of lower limbs. ${ }^{4}$ At least $15 \%$ of DFU patients will suffer an amputation of the thigh or leg. The risk of a patient with diabetes developing a foot ulcer throughout life can reach $25 \%$, and it is known that every 30 seconds a lower limb amputation, caused by diabetes, occurs worldwide. ${ }^{6}$ Therefore, DFU is considered one of the complications of diabetes that result in higher costs given that the final solution is often an amputation. ${ }^{5}$

Therefore, there are two types of diabetic foot: the neuropathic diabetic foot caused by diabetic polyneuropathy, and the neuroischemic diabetic foot caused by arterial occlusion that is, in most cases, associated to the neuropathy. Diabetic foot lesions arise due to insensitivity caused by sensory/motor neuropathy and/or ischemia caused by atherosclerotic lesions in the lower limb. Preferential impairment of one of these two structures, nerves or blood vessels, will condition the appearance of a neuropathic or neuroischemic foot. ${ }^{6,8}$

Regarding the etiology of ulcers and diabetic foot type, the literature suggests a greater prevalence of neuroischemic ulcers ranging between 59 and $74 \%$. The prevalence of neuropathic ulcers has been falling, ranging from 26 to $45 \% .7,9,10$

The presence of an ulcer has serious emotional, social and economic implications, ${ }^{11,12}$ decreasing considerably the patient's mobility, autonomy, and quality of life. ${ }^{13,15}$ In addition, ulcers can be a source of pain, also contributing to progressive degradation of the diabetic patient's quality of life. ${ }^{16,17}$ In the presence of the most severe form of PVD, trophic lesions may appear, such as ischemic ulcers and necrosis of the toes, responsible for the worsening of pain, which may already be present due to the disease itself. ${ }^{18,20}$ In the neuroischemic foot, the pain due to ischemia can be intense but due to the effects of diabetic neuropathy, may also be less dramatic (or even absent).${ }^{18}$ Neuropathic pain is described as something that bothers an individual, not necessarily a very strong pain, even though, in some cases, the symptoms of pain can be intense. ${ }^{21}$ Patients usually describe the pain as "pins and needles", "tingling" or "burning". 22,23

Therefore, the presence of either PVD or painful neuropathy, or both, can contribute to the presence of pain and considerably diminish the quality of life of diabetic patients. ${ }^{24}$ According to the existing studies, neuropathic pain is associated with a lower quality of life, ${ }^{22}$ high levels of anxiety and depression, as well as impaired sleep. ${ }^{25,26}$ Furthermore, neuropathic pain causes disability and $1 / 3$ of patients need help to walk (crutches or wheelchair). ${ }^{27,28}$ There are several pharmacological and non-pharmaco- logical interventions ${ }^{29}$ whose main goal is the management and reduction of pain as well as the promotion of a satisfactory general functioning, in the patient. ${ }^{30}$

The goes of this study were the following: 1) to provide a sociodemographic and clinical characterization of a sample of patients with DFU indicated for amputation surgery 2) to characterize the pain in terms of intensity and interference in daily life activities, and 3) to understand the relationships between the intensity and interference of pain and sociodemographic and clinical variables. Lastly, with this study we hope to gain knowledge regarding the demographic, social and clinical characteristics of patients with DFU as well as the prevalence of pain, its intensity and interference in patient's daily life activities in order to develop appropriate and effective multidisciplinary interventions.

\section{Methods}

This study was conducted at the Diabetic Foot Clinic of five hospitals and two Vascular Surgery Departments in the north of Portugal, in order to characterize patients with type 2 diabetes and diabetic foot referred for amputation surgery. The study was conducted in the period between June 2013 and June 2015.

This was a longitudinal study, but in the present paper we are only presenting data from the first evaluation, i.e. data relating to patients at the time of hospitalization due to DFU. The clinical data was obtained from health professionals' charts. The criteria for inclusion in the sample was: having type 2 diabetes and diabetic foot ulcer; being referred for an amputation surgery; being older than 18 years; showing auto- and allopsychic orientation; having the ability to interpret and answer orally and not having a diagnosis of severe psychiatric pathology (e.g. psychosis). The study was approved by the Ethics Committee of the six hospitals.

The instruments used were:

- Sociodemographic and clinical questionnaire: This questionnaire took into consideration demographic, social and patients' clinical data.

- Brief pain inventory::31,32 The BPI consists of 15 items assessing the presence, location, intensity, and interference of pain, therapeutic strategies used and effectiveness of the pain treatment. It includes two subscales: one assessing intensity of pain consisting of 4 items (maximum, minimum, average and current pain), and another assessing the interference of pain consisting of 7 items (general activity, mood, walking ability/mobility, normal work (outside the home and housework/ 
DLAs), relations with others, sleep, enjoyment of life), in a numeric rating scale (NRS) (from 0 to 10 with $0=$ no interference and $10=$ interferes completely). High results indicate greater severity of pain and greater interference of pain. A score of 3 is considered the cutoff score indicating significant pain. ${ }^{33-35}$ The scale assessing intensity of pain showed an alpha of 82 while the interference assessment scale presented an alpha of 89 .

- Douleur Neuropathique 4 (DN4) questionnaire:36,37 Consisting of 10 items, comprises two questions about pain (corresponding to seven items) and two tests of cutaneous sensitivity (corresponding to three items). In this study, only the two questions about pain, comprising seven items, that include the following signs and descriptors of neuropathic pain were used: "The pain presents itself in this way": Burning, sensation of painful cold, electric shocks; and "in the same region as the pain, one or more of the following symptoms is also felt": Tingling, pins and needles, numbless and itching. This questionnaire was used to characterize the pain and was not included in the inferential statistical analysis.

The data analysis included descriptive statistics to characterize the sample in terms of sociodemographic and clinical variables. A Pearson correlation was performed to assess the relationships between interval variables and a Point Bisserial correlation to analyze relationships between dichotomous variables.

\section{Results}

\section{Sociodemographic characteristics of the sample}

The 206 patients were hospitalized due to a diabetic foot ulcer and were referred for amputation surgery. $72.3 \%(n=149)$ were male, with an average age of $66.1(\mathrm{SD}=10.88 \%)$ years, the youngest patient was 36 and the oldest 90 years old, and presented 4.55 years $(\mathrm{SD}=3.14)$ of formal education. About $63 \%$ of the sample was married, with $76.8 \%(\mathrm{n}=156)$ being retired, while the remaining were still professionally active. Almost all patients reported having a caregiver ( $\mathrm{n}=178,86.4 \%)$, most often the spouse $(50 \%, n=103)$ followed by their offspring $(24.3 \%, \mathrm{n}=50)$.

In terms of mobility, $37.9 \%(n=78)$ of the sample reported having used crutches for daily activities, on average, for 17 months $(\mathrm{SD}=43.1), 12.1 \%(\mathrm{n}=25)$ had used a wheelchair, on average for 15 months $(\mathrm{SD}=15.8)$, and only $2.9 \%(n=6)$ were bedridden, for 11 months on average $(\mathrm{SD}=13.5)$.

As for access to primary health care, $94.2 \%$ of participants $(\mathrm{n}=194)$ reported having a family physician, $65.5 \%$ $(\mathrm{n}=135)$, had attended 4 annual consultations at their health care center in the previous year, and $62 \%(\mathrm{n}=128)$ underwent monitoring at a Diabetic Foot Clinic, mainly in the hospital of their area of residence $(40.6 \%, n=52)$ or the health care center $(59.4 \%, \mathrm{n}=76)$.

\section{Clinical characteristics of the sample}

Patients presented a diagnosis of type 2 diabetes for an average of 18 years $(\mathrm{SD}=11.56)$ ranging between 1 month and 53 years and a diagnosis of diabetic foot on average for 4 years $(\mathrm{SD}=4.59)$ ranging between 1 month and 22 years. One hundred forty two $(68.9 \%)$ patients were treated with insulin and 85 (41.3\%) had already been hospitalized in the previous year due to DFU. Regarding the type of foot, $26.2 \%$ presented a neuropathic foot and $73.8 \%$ a neuroischemic foot. The remaining clinical characteristics of the sample are presented in Table 1.

\section{TABLE 1 Clinical characteristics of the sample.}

\begin{tabular}{|c|c|c|}
\hline \multirow[t]{2}{*}{ Foot type } & Neuropathic & 26.2 \\
\hline & Neuroischemic & $73.8 \%$ \\
\hline \multirow[t]{5}{*}{ Complications from diabetes } & Yes & $99.5 \%$ \\
\hline & Nephropathy & $49.5 \%$ \\
\hline & Retinopathy & $65 \%$ \\
\hline & Neuropathy & $97.1 \%$ \\
\hline & Macrovascular disease & $83.5 \%$ \\
\hline \multirow[t]{2}{*}{ Other chronic diseases } & Yes & $24.3 \%$ \\
\hline & No & $75.7 \%$ \\
\hline \multirow{9}{*}{$\begin{array}{l}\text { Risk factors for cardiovascular } \\
\text { disease }\end{array}$} & Yes & $93.7 \%$ \\
\hline & Dyslipidemia & $77.7 \%$ \\
\hline & High blood pressure & $86.4 \%$ \\
\hline & Currently smoker & $7.3 \%$ \\
\hline & Smoking history & $51 \%$ \\
\hline & Alcohol consumption & $31.1 \%$ \\
\hline & BMI: healthy weight & $29.6 \%$ \\
\hline & Excess weight & $47.6 \%$ \\
\hline & Obesity & $16 \%$ \\
\hline \multirow[t]{2}{*}{ Metabolic control } & $<7.5 \%$ & $29.8 \%$ \\
\hline & $>7.6 \%$ & $70.2 \%$ \\
\hline \multirow[t]{4}{*}{ Location of the ulcer } & Leg & $4.9 \%$ \\
\hline & Foot & $29.1 \%$ \\
\hline & Heel & $2.9 \%$ \\
\hline & Toes & $63.1 \%$ \\
\hline \multirow[t]{4}{*}{ Duration of the ulcer } & Up to 6 weeks & $42.2 \%$ \\
\hline & Up to 6 months & $34.5 \%$ \\
\hline & More than 6 months & $12.6 \%$ \\
\hline & More than 1 year & $10.7 \%$ \\
\hline
\end{tabular}




\section{Characterization of the pain}

From the total sample, $58.7 \%(n=121)$ of patients presented pain in the lower limb. In relation to the descriptors of neuropathic pain, the descriptor "pins and needles" was the most reported followed by "burning" and "numbness" pain, with each patient referring to the three neuropathic pain descriptors on average $(\mathrm{SD}=1.2)$. Almost all patients who felt pain mentioned taking pain medication at home $(94.2 \%$, $n=114)$, especially acetaminophen (32.5\%), the combination of acetaminophen and opioids (27.5\%) and 7.9\% gabapentinoids. Nearly half of patients (49.6\%) reported that the pain medication provided relief between 50 to $100 \%$, while the remaining 50.4\% indicated lower scores for pain relief.

Patients report pain mainly in the foot $(65.3 \%, \mathrm{n}=79)$ for 23 weeks on average ( $\mathrm{SD}=21.9)$, ranging from 1 to 96 weeks. About $36 \%$ of patients $(n=43)$ reported pain elsewhere. The pain often was reported as having a daily frequency $(51.2 \%$, $\mathrm{n}=62)$, followed by constant pain $(42.1 \%, \mathrm{n}=51)$. About $36 \%$ of patients $(n=43)$ reported pain elsewhere.

As for the intensity of the pain, in the last week, the average of the maximum intensity was above 3 (considered the cutoff score for significant pain) and the minimal pain (scores of 1 or 2) was still indicative of non-absence pain in patients (Figure 1). Similarly, for the level of interference of pain the results showed that all areas were impacted showing significant scores (above 3 ) and, therefore, impaired (Figure 2).

Relationship between intensity/interference of pain and clinical and sociodemographic variables

Intensity of pain was positively related with age $(\mathrm{r}=.292$, $\mathrm{p}=<.01)$, pain duration $(\mathrm{r}=.230, \mathrm{p}=>.05)$ and ulcer duration $(\mathrm{r}=.210, \mathrm{p}<.05)$. Interference of pain was positively related with age $(\mathrm{r}=.183, \mathrm{p}<.05)$ and number of hospital- izations in the last year $(\mathrm{r}=.240, \mathrm{p}<.01)$ and negatively with type of foot $\left(r=-.250, \mathrm{p}^{<} .01\right)$, i.e. patients with neuropathic foot showed less interference of pain.

\section{Discussion}

There are several studies that suggest that the sociodemographic variables play an important role in diabetic foot ulceration and not just the clinical factors. ${ }^{38-41}$ In the study by DeBerardis et al. ${ }^{39}$ the prevalence of diabetic foot complications was higher in older patients, those with limited formal education and a low sociodemographic status, divorced or widowed with greater duration of diabetes, high HbA1c, treated with insulin, and with micro and macrovascular complications. Our results do, in fact, corroborate the existing literature suggesting that diabetic foot ulcers in patients, scheduled for amputation, are more prevalent in males (occurring twice in men than women). ${ }^{11-41}$ However, it is important to take in consideration that the youngest patient was 39 years old and the mean age was 66 years old, indicating that half the sample was 67 years old (median) or less, revealing a relatively young sample. This sample was characterized by a low education level, with most of the patients presenting five years of formal education (elementary school), which may hinder the understanding of the information provided by health professionals and, therefore, impact adherence to self-care behaviors. ${ }^{17}$ More than half of the sample was retired (due to age or disability), while about $23 \%$ were still active. Professional inactivity is considered a risk factor for diabetic foot ulceration ${ }^{38,42}$ and the percentage of patients still employed highlights the negative impact that DFU may have at personal and financial levels. In fact, DFU recovery may lead to unemployment, prolonged medical leave and economic costs to the patient and the family. ${ }^{7}$

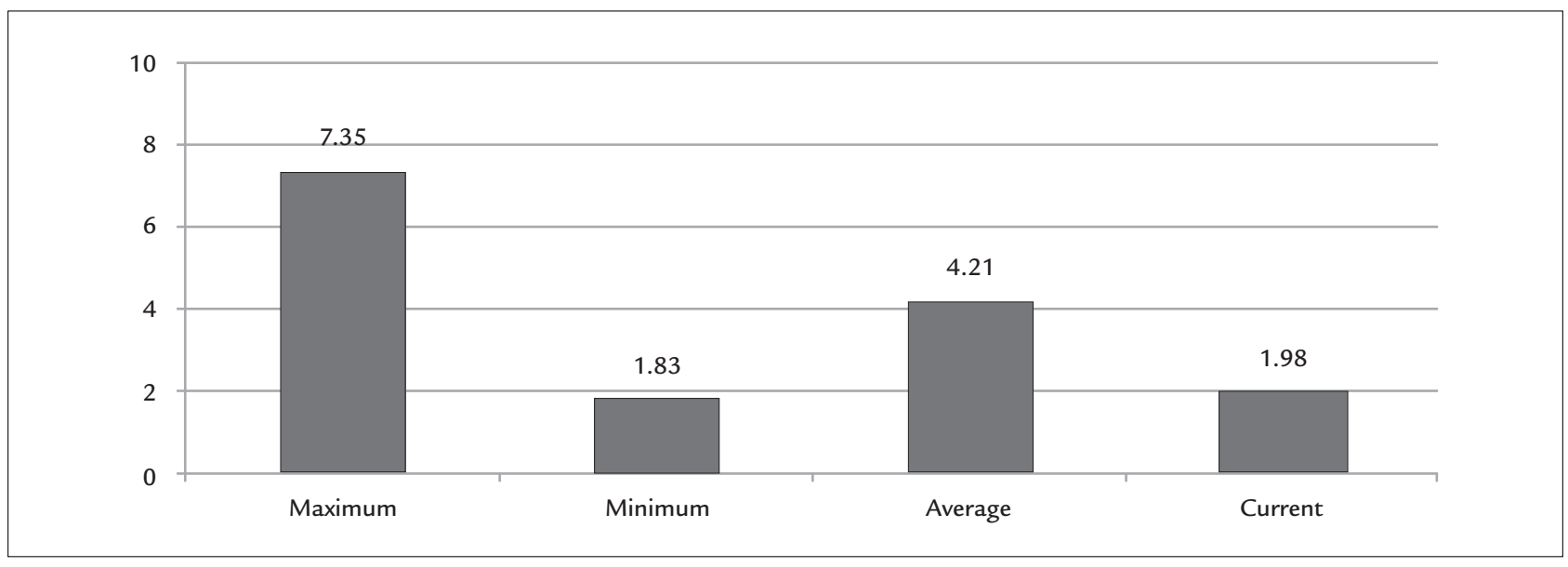

FIGURE 1 Mean of pain intensity. 


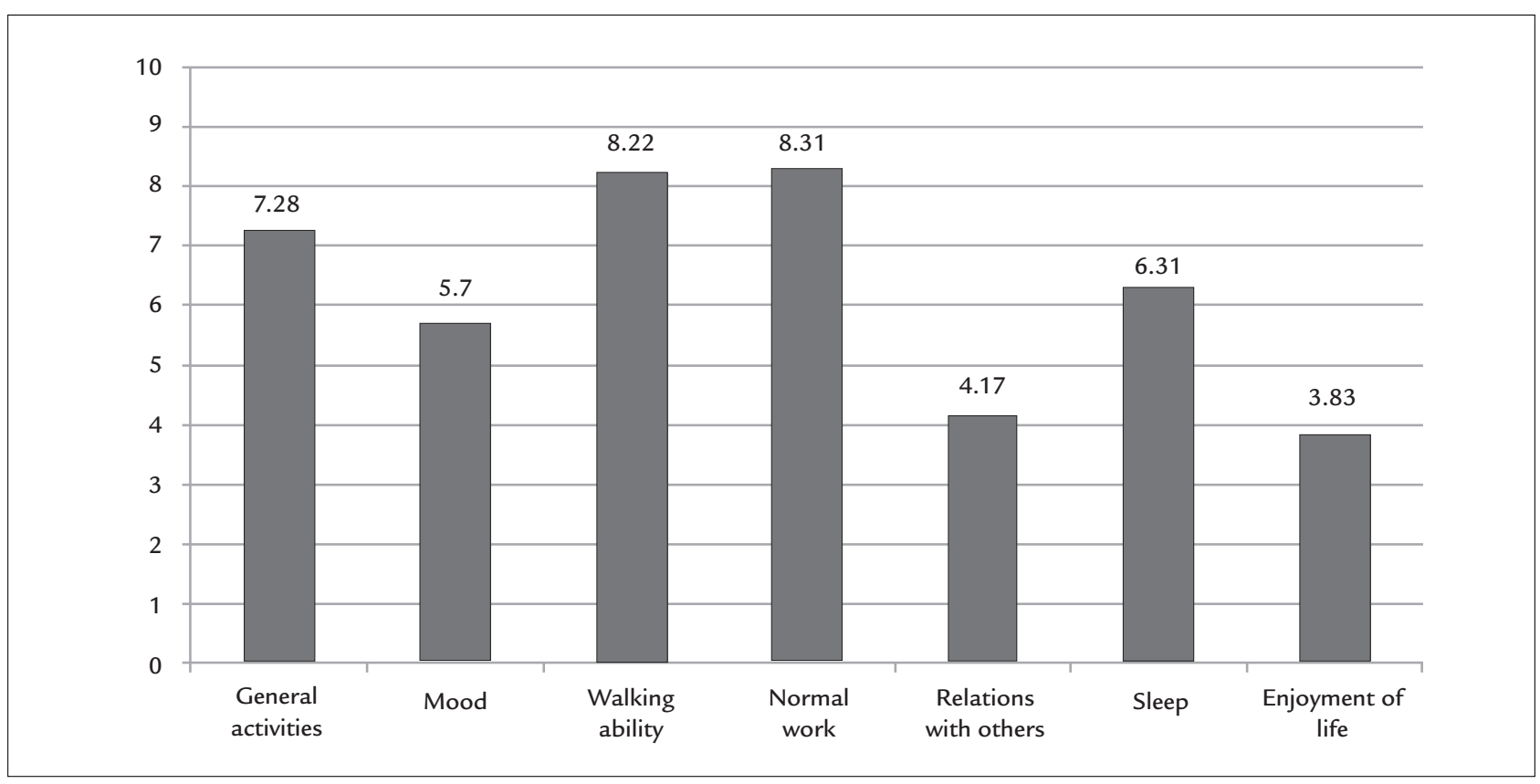

FIGURE 2 Mean of pain interference.

Regarding marital status, almost all patients were married and the main caregiver reported was the patient's spouse or the offspring. This fact shows the importance of the role of the family, that seem to be responsible to help the patient take care of his/her feet, especially when presenting diabetes complications that allow hinder foot daily selfcare behaviors (e.g. retinopathy) or other chronic diseases that affect adherence to self-care behaviors, such as cognitive deficits. A study by Macfarlane and Jeffcoate ${ }^{43}$ emphasized the importance of patient and family education in foot self-care, as only $56 \%$ of the lesions were detected by the patients themselves. Taking into account the role of the family in the patient's adherence to self-care and the detection of lesions, the Governmental Norm of the National Portuguese Health System - 5/PNPCD ${ }^{44}$ stated that patients and families' education regarding foot care was a priority in order to prevent the emergence of new ulcers, as well as to manage the seriousness of the current clinical symptoms.

This sample of patients presented a functional mobility level, if we take into account that they all had lower limb ulcers and had been referred for amputation surgery. While about $38 \%$ of the sample needed crutches to move, only $12 \%$ needed a wheelchair, and only six patients were bedridden and, therefore, dependent on the care of significant others. Studies have been reporting that foot ulcers can cause serious disability, decreased mobility and long periods of hospitalization, and are, therefore, considered an economic burden for families and the health system. ${ }^{45,46}$
As for access to primary health care, almost the entire sample reported having a family physician although only half of the participants reported attending four annual consultations at the health center. Fortunately, more than half of the participants mentioned being monitored by a Diabetic Foot Clinic, at the hospital, since they are at high-risk for amputation and monitoring is no longer undertaken at primary health care services, but by multidisciplinary teams in hospitals. However, there are several factors that influence the degree to which the patient is capable of performing self-care, such as personal health, access to health care, education about foot care and formal and informal support. ${ }^{47}$ Unfortunately, foot care seems to be the least performed self-care in diabetes. ${ }^{39,48}$

With regard to the characteristics of diabetes, patients presented the disease for an average of 18 years and diabetic foot for an average of 4 years. Given the long duration of diabetes, it is understandable that the sample presented complications from diabetes, with the most prevalent being diabetic neuropathy and macrovascular complications such as cardiovascular, cerebral and peripheral vascular disease..$^{38,42,49}$

In this sample, neuroischemic foot had a higher prevalence than neuropathic foot, as recent studies have also reported. ${ }^{7,9,10}$ The change in the prevalence of ulcers may be due to patients' age, given that, as they get older, they develop more complications from diabetes. Also, the majority of patients have ulcers in the lower limbs that have developed in a period of 1 to 6 weeks, predominantly in 
the toes followed by the foot. This location is more subject to ordinary trauma in the everyday life, and is anatomically more susceptible to the development of tissue necrosis.

More than half of the sample reported pain and most reported pain descriptors were "pins and needless", "burning" and "numbness". These descriptors are common in the description of neuropathic pain..$^{22,23,27}$ The literature indicates that the pain is associated with a poor quality of life $\mathrm{e}^{22}$ with consequences in terms of quality of sleep, psychological morbidity and mobility impairments. ${ }^{25,27}$ In fact, the impact of pain on patient functioning is evident and, in this study, the maximum intensity of pain reported by patients was significant and the minimal pain reported was also indicative that patients lived daily with non-absence pain. Regarding interference, the pain significantly interfered with all functional areas of life. Only the item that assessed enjoyment of life was above the cutoff score of 3 . Also, almost half of the sample of patients with pain reported that analgesic medication relieved between 50 and 100\% of the pain, which indicates some effectiveness of medication on pain management, even though the remaining of the sample reported lower relief. The pain medication recorded in this study includes the medication that patients usually take at home, prescribed by their doctors, and not the medication administered during the period of hospitalization which, understandably, has a higher efficacy. Jensen et al. ${ }^{50}$ report that only $1 / 3$ of patients report $50 \%$ of pain relief from medication. However if the treatment for pain causes at least $30 \%$ of relief, it is considered effective. ${ }^{51}$

We found that the oldest patients with a longer duration of ulcer and pain presented a higher intensity of pain. Patients with more number of hospitalizations and with a neuroischemic foot reported higher interference of pain, as expected.

The prevention of ulcers requires a strict metabolic control, good adjustment to chronic illness in general, and especially regular and consistent feet inspection. ${ }^{38}$ However, most of the interventions that have been performed, in this population, include only the provision of information and behavioral skills training, without taking into account the psychosocial process underlying foot care adherence ${ }^{52}$ in the patient and the family support. ${ }^{43}$

This study has some limitations such as the use of self report measures and the sample size regarding the number of patients with neuropathic foot. In the future it would be important to assess the interference and intensity of pain after surgery and during the rehabilitation process in order to promote DFU patients' quality of life.

\section{Conclusion}

The results of this study corroborate international studies to the extent that this sample of DFU patients does not differ from international samples, highlighting the homogeneity of the social, demographic, and clinical characteristics that characterize this population.

According to the results, this study emphasizes the need for prevention regarding foot care as well as the need for intervention in patients that are already diagnosed with DFU, particularly those that report pain. As such, in DFU patients should be the target of systematic multidisciplinary interventions, that focuses on the regular assessment of adherence to the recommended self-care behaviors and take also into consideration whether the patient receives support from a caregiver or family member. The need for psychological monitoring should also be considered when the interference of pain on DLAs is high and the patient has no family support, in order to promote pain coping strategies that foster psychological wellbeing.

Pain, in DFU patients, is a specific health problem with unique characteristics. It is therefore urgent to identify patients who report pain and intervene preventively before it becomes chronic associated with amputation. The intervention should be multidisciplinary and involve all the health professionals who can provide pain management, including the family member or the patient's caregiver.

The literature has been suggesting that the risk of foot complications can be reduced by 49 to $85 \%$ through preventive measures, patient education, and foot self-care behaviors, with structured diabetes health care consultations being the most promising measure to reduce amputation (major) in patients with diabetes. ${ }^{53-55}$

The psychological wellbeing of the patient plays an important role in the management of the disease and in adherence to self-care, in diabetes. The literature has shown that individual and family psychological variables as well as health system variables play a major role in adherence to self-care. ${ }^{56-58}$ For this reason, health professionals who deal with DFU patients should take into account the patient's biopsychosocial context. The psychosocial problems that patients present need to be addressed since they may compromise the adherence to self- care behaviors and hinder the process of adjustment to amputation.

\section{AcKNOWLeDGments}

The authors would like to thank the contribution of health professionals from the Multidisciplinary Diabetic Foot Clinic of Centro Hospitalar do Porto, Centro Hospitalar de Vila Nova de Gaia/Espinho, Centro Hospitalar de Tâ- 
mega and Sousa, the Local Health Unit of Alto Minho and the Vascular Surgery Service at Hospital de Braga. The authors also wish to thank all patients who agreed to participate in this study.

\section{Resumo}

Características sociodemográficas e clínicas de doentes com pé diabético

Introdução: o pé diabético é uma das complicações mais graves da diabetes, afetando cerca de $15 \%$ dos indivíduos com diabetes, e é a maior causa de amputação de membros inferiores de origem não traumática. Este estudo apresenta uma caracterização sociodemográfica e clínica de doentes com pé diabético indicados para cirurgia de amputação.

Método: estudo transversal com 206 doentes com diabetes tipo 2 e pé diabético indicados para cirurgia de amputação. Foram recolhidos dados sociodemográficos e clínicos. Intensidade e interferência da dor foram avaliadas por meio do Brief Pain Inventory e os descritores da dor, pelo Douleur Neuropathique 4.

Resultados: a maioria dos doentes era do sexo masculino, com baixa escolaridade e uma média de idade de 66 anos. Apresentava diagnóstico de diabetes tipo 2 havia 18 anos e pé diabético havia 4 anos. Cerca de 59\% dos doentes apresentavam dor no membro inferior, interferindo significativamente em todas as áreas de funcionamento.

Conclusão: as variáveis sociodemográficas desempenham um papel importante na ulceração do pé diabético. As úlceras neuropáticas são mais facilmente preveníveis; portanto, é importante o acompanhamento sistemático dos doentes com neuropatia. Nos doentes com pé neuroisquêmico, estratégias para lidar/gerir a dor de forma mais eficaz são necessárias. A intervenção deve ser multidisciplinar e considerar os fatores sociodemográficos e clínicos, a presença, intensidade e interferência da dor nas atividades de vida diária do doente, bem como a presença de suporte da família ou de um cuidador.

Palavras-chave: diabetes mellitus tipo 2, complicações do diabetes, pé diabético.

\section{References}

1. Diabetes: Factos e Números 2014: Relatório Anual do Observatório Nacional da Diabetes. Sociedade Portuguesa de Diabetologia. [cited 2016 Apr 13]. Available from: http://spd.pt/images/ond_2015.pdf.

2. American Diabetes Association. Standards of Medical Care in Diabetes 2014 Diabetes Care. 2014; 37(1):1-67.
3. Cuidados de Saúde a Portadores de Diabetes Mellitus. Entidade Reguladora de Saúde. [cited 2014 Apr 23]. Available from: https://www.ers.pt/uploads/ writer_file/document/139/DM_Relatorio_Final.pdf

4. Armstrong DG, Nguyen HC, Lavery LA, van Schie CH, Boulton AJ, Harkless LB. Off-loading the diabetic foot wound: a randomized clinical trial. Diabetes Care. 2001; 24(6):1019-22.

5. Anichini R, Zecchini F, Cerretini I, Meucci G, Fusilli D, Alviggi L, et al Improvement of diabetic foot care after the Implementation of the International Consensus on the Diabetic Foot (ICDF): results of a 5-year prospective study. Diabetes Care. 2007; 75(2):153-8.

6. Duarte N, Gonçalves A. Pé diabético. Angiol Cir Vasc. 2011; 7(2):65-79.

7. Rathur HM, Boulton AJ. The diabetic foot. Clin Dermatol. 2007; 25(1):109-20.

8. Serra L. O pé diabético: manual para a prevenção da catástrofe. 2.ed. Porto: Lidel, 2008.

9. Madanchi N, Tabatabaei-Malazy O, Pajouhi M, Heshmat R, Larijani B, Mohajeri-Tehrani MR. Who are diabetic foot patients? A descriptive study on 873 patients. J Diabetes Metab Disord. 2013; 12:36.

10. Ashraf MN, Rehman K, Malik KI, Iqbal GS. Epidemiology and outcome in patients of diabetic foot. J Ayub Med Coll Abbottabad. 2011; 23(1):122-4.

11. Singh N, Armstrong DG, Lipsky BA. Preventing foot ulcers in patients with diabetes. JAMA. 2005; 293(2):217-28.

12. Ulbrecht JS, Cavanagh PR, Caputo GM. Foot problems in diabetes: an overview. Clin Infect Dis. 2004; 39(Suppl 2):73-82.

13. Ragnarson Tennvall G, Apelqvist J. Health-related quality of life in patients with diabetes mellitus and foot ulcers. J Diabetes Complications. 2000; 14(5):235-41.

14. Valensi P, Girod I, Baron F, Moreau-Defarges T, Guillon P. Quality of life and clinical correlates in patients with diabetic foot ulcers. Diabetes Metab. 2005; 31 (3 Pt 1):263-71.

15. Yekta Z, Pourali R, Ghasemi-Rad M. Comparison of demographic and clinical characteristics influencing health-related quality of life in patients with diabetic foot ulcers and those without foot ulcers. Diabetes Metab Syndr Obes. 2011; 4:393-9.

16. Iversen MM, Midthjell K, Tell GS, Moum T, Østbye T, Nortvedt MW, et al. The association between history of diabetic foot ulcer, perceived health and psychological distress: The Nord-Trondelag Health Study. BMC Endocr Disord. 2009; 9(18):1-7.

17. Vileikyte L, Rubin RR, Leventhal H. Psychological aspects of diabetic neuropathic foot complications: an overview. Diabetes Metab Res Rev. 2004; 20(Suppl 1):13-8.

18. Jörneskog $\mathrm{G}$. Why critical limb ischemia criteria are not applicable to diabetic foot and what the consequences are. Scand J Surg. 2012; 101(2):114-8.

19. Norgren L, Hiatt WR, Dormandy JA, Nehler MR, Harris KA; Fowkes FG; TASC II Working Group. Inter-Society Consensus for the Management of Peripheral Arterial Disease (TASC II). J Vasc Surg. 2007; 45(Suppl S):S5-67.

20. Hirsch AT, Criqui MH, Treat-Jacobson D, Regensteiner JG, Creager MA, Olin JW, et al. Peripheral arterial disease detection, awareness, and treatment in primary care. JAMA. 2001; 286(11):1317-24.

21. Gilbey SG. Neuropathy and foot problems in diabetes. Clin Med (Lond). 2004; 4(4):318-23.

22. Davies M, Brophy S, Williams R, Taylor A. The prevalence, severity, and impact of painful diabetic peripheral neuropathy in type 2 diabetes. Diabetes Care. 2006; 29(7):1518-22

23. Ziegler D. Painful diabetic neuropathy: advantage of novel drugs over old drugs? Diabetes Care. 2009; 32(Suppl 2):S414-9.

24. Vaz C, Duarte VM, Santos AR, Valente P, Paul C, Bastos R, et al. Doença arterial periférica e qualidade de vida. Angiol Cir Vasc. 2013; 9(1):1-7.

25. Gore M, Brandenburg NA, Dukes E, Hoffman DL, Tai KS, Stacey B. Pain severity in diabetic peripheral neuropathy is associated with patient functioning, symptom levels of anxiety and depression, and sleep. J Pain Symptom Manage. 2005; 30(4):374-85.

26. Zelman DC, Brandenburg NA, Gore M. Sleep impairment in patients with painful diabetic peripheral neuropathy. Clin J Pain. 2006; 22(8):681-5.

27. Galer BS, Gianas A, Jensen MP. Painful diabetic polyneuropathy: epidemiology, pain description, and quality of life. Diabetes Res Clin Pract. 2000; 47(1):123-8.

28. Lalli P, Chan A, Garven A, Midha N, Chan C, Brady S, et al. Increased gait variability in diabetes mellitus patients with neuropathic pain. J Diabetes Complications. 2013; 27(3):248-54.

29. Direção Geral de Saúde. Terapêutica dor neuropática. Circular Normativa n. 043/2011. Lisboa: DGS, [cited 2014 Apr 23]. Available from: http://www dgs.pt/normas-clinicas.aspx. 
30. American Academy of Neurology. Diabetic nerve pain: a guide for patients and families. USA: American Academy of Neurology Foundation 2011. [cited 2014 Apr 23]. Available from: https://www.aan.com/uploadedFiles/3Practice Management/2Quality_Improvement/2Patient_Safety/3Drug_and_Device_ Safety/nerve.pdf.

31. Cleeland C, Syrjala K. How to assess cancer pain. In: Turk D, Melzack R (eds.) Handbook of pain assessment. New York: Guilford Press, 1992. p.362-87.

32. Azevedo LF, Pereira AC, Dias C, Agualusa L, Lemos L, Romão J, et al. Tradução, adaptação cultural e estudo multicêntrico de validação de instrumentos para rastreio e avaliação do impacto da dor crónica: versão portuguesa do questionário Brief Pain Inventory (BPI), período de referência última semana. Rev Dor. 2007; 15(4):6-40.

33. Bodian CA, Freedman G, Hossain S, Eisenkraft JB, Beilin Y. The visual analog scale for pain: Clinical significance in postoperative patients. Anesthesiology. 2001; 95(6):1356-61

34. Dihle A, Helseth S, Paul SM, Miaskowski C. The exploration of the establishment of cutpoints to categorize the severity of acute postoperative pain. Clin J Pain. 2006; 22(7):617-24

35. Hartrick CT, Kovan JP, Shapiro S. The numeric rating scale for clinical pain measurement: A ratio measure? Pain Pract. 2003;3(4):310-6.

36. Bouhassira D, Attal N, Alchaar H, Boureau F, Brochet B, Bruxelle J, et al. Comparison of pain syndromes associated with nervous or somatic lesions and development of a new neuropathic pain diagnostic questionnaire (DN4) Pain. 2005; 114(1-2):29-36

37. Bouhassira D, Lanteri-Minet; M, Attal N, Laurent B, Touboul C. Prevalence of chronic pain with neuropathic characteristics in the general population. Pain. 2008; 136(3):380-7.

38. Akca AT, Cinar S. Comparison of psychosocial adjustment in people with diabetes with and without diabetic foot ulceration. Aust J Adv Nurs. 2008; 25(4):87-96.

39. DeBerardis G, Pellegrini F, Franciosi M, Belfiglio M, DiNardo B, Greenfield $\mathrm{S}$, et al. Are type 2 diabetic patients offered adequate foot care? The role of physician and patient characteristics. J Diabetes Complications. 2005; 19(6):319-27.

40. Mayfield JA, Reiber GE, Sanders LJ, Janisse D, Pogach LM. Preventive foot care in people with diabetes. Diabetes Care. 1998; 21(12):2161-77.

41. Bowering CK. Diabetic foot ulcers. Can Fam Physician. 2001; 47:1007-16

42. Leymarie F, Richard J, Malgrange D. Factors associated with diabetic patients at high risk for foot ulceration. Diabetes Metab. 2005; 31(6):603-5.

43. Macfarlane RM, Jeffcoate WJ. Factors contributing to the presentation of diabetic foot ulcers. Diabetic Med. 1997; 14(10):867-70

44. Direção Geral de Saúde. Pé diabético: Programa Nacional de Prevenção e Controlo da Diabetes (PNPCD) Circular Normativa n. 5/2010. Lisboa: DGS [cited 2014 Apr 23]. Available from: http://www.dgs.pt/normasclinicas.aspx.
45. Goodridge D, Trepman E, Embil JM. Health-related quality of life in diabetic patients with foot ulcers. J Wound Ostomy Continence Nurs. 2005; 32(6):368-77

46. Margolis DJ, Malay DS, Hoffstad OJ. Economic burden of diabetic foot ulcers and amputations. 2011 Mar 8. In: DataPoints Publication Series. Rockville (MD): Agency for Healthcare Research and Quality (US) 2011. [cited 2014 Apr 23]. Available from: http://www.ncbi.nlm.nih.gov/books/NBK65152/.

47. Bell RA, Arcury TA, Snively BM, Smith SL, Stafford JM, Dohanish R, et al Diabetes foot self-care practices in a rural, triethnic population. Diabetes Educ. 2005; 31(1):75-83.

48. Schmidt S, Mayer H, Panfil EM. Diabetes foot self-care practices in the German population. J Clin Nurs. 2008; 17(21):2920-6.

49. Ribu L, Hanestad BR, Moum T, Birkeland K, Rustoen T. A comparison of the health-related quality of life in patients with diabetic foot ulcers, with a diabetes group and a nondiabetes group from the general population. Qual Life Res. 2007; 16(2):179-89.

50. Jensen T, Backonja MM, Hernández Jiménez S, Tesfave S, Valensi P, Ziegler D. New perspectives on the management of diabetic peripheral neuropathic pain. Diabetes Vasc Dis Res. 2006; 3(2):108-19.

51. Farrar JT, Young JP Jr, LaMoreaux L, Werth JL, Poole RM. Clinical importance of changes in chronic pain intensity measured on an 11-point numerical pain rating scale. Pain. 2001; 94(2):149-58.

52. Vileikyte L, Gonzalez JS, Leventhal H, Peyrot M, Rubin RR, Garrow A, et al. Patient interpretation of neuropathy questionnaire: an instrument for assessment of cognitive and emotional factors associated with foot self-care. Diabetes Care. 2006; 29(12):2617-24.

53. Weck M, Slesaczeck T, Paetzold H, Münch D, Nanning T, von Gagern G, et al. Structured health care for subjects with diabetic foot ulcers results in a major reduction of amputation rates. Cardiovasc Diabetol. 2013; 12:45.

54. Prompers L, Schaper N, Apelqvist J, Edmonds M, Jude E, Mauricio D, et al. Prediction of outcome in individuals with diabetic foot ulcers: focus on the differences between individuals with and without peripheral arterial disease. The EURODIALE Study. Diabetologia. 2008; 51(5):747-55.

55. Gershater M, Löndahl M, Nyberg P, Larsson J, Thörne J, Eneroth M, et al Complexity of factors related to outcome of neuropathic and neuroischaemic/ ischaemic diabetic foot ulcers: a cohort study. Diabetologia. 2009; 52(3):398-407.

56. Pereira MG, Pedras S, Machado JC. Family variables as moderators between beliefs towards medicines and adherence to self-care behaviors and medication in type 2 diabetes. Fam Sys Health. 2014; 32(2):198-206.

57. Pereira MG, Costa V, Oliveira D, Ferreira G, Pedras S, Sousa MR, et al. Patients and spouses' contribution toward adherence to self-care behaviors in type 2 diabetes. Res Theory Nurs Pract. 2015; 29(4):276-96.

58. Pereira MG, Pedras S, Machado JC, Ferreira G. Partners' representations of diabetes as mediators between patients' representations and adherence to self-care behaviors, in type 2 diabetes. Psychol Health Med. 2015 Dec 30. [Epub ahead of print]

\section{ERRATA}

http://dx.doi.org/10.1590/1806-9282.62.04.385

In the article "Sociodemographic and clinical characteristics of patients with diabetic foot ulcer", DOI: http://dx.doi.org/10.1590/18069282.62.02.171 published in the journal Rev Assoc Med Bras, 62(2):171-178, on page 171, where it reads:

"Results: Most patients were male, with little formal education and a mean age of 66 years. They had been diagnosed with type 2 diabetes for 18 years in average, and diagnosed with diabetic foot ulcer in average 3 years prior to the assessment. About $59 \%$ of patients experienced pain in the lower limb that significantly interfered with all areas of their functioning."

Change to:

"Results: Most patients were male, with little formal education and a mean age of 66 years. They had been diagnosed with type 2 diabetes for 18 years on average, and with diabetic foot ulcer on average 4 years prior to the assessment. About $59 \%$ of patients experienced pain in the lower limb that significantly affect all areas of their functioning."

Where it reads:

"Financial support: Fundação para a Ciência e Tecnologia (FCT)"

Change to:

"Financial support: This study was conducted at the Psychology Research Centre (PSI/01662), University of Minho, and supported by the Portuguese Foundation for Science and Technology and the Portuguese Ministry of Science, Technology and Higher Education through national grants and co-funded by the FEDER through COMPETE2020 under the PT2020 Partnership Agreement (POCI-01-0145-FEDER-007653)" 